\title{
Sorption isotherms of tobacco (Nicotiana tabacum L.) seeds
}

\author{
Lazar Lazarov ${ }^{1}$, Nesho Toshkov ${ }^{2}$, Tanya Ivanova ${ }^{1}$, Venelina Popova ${ }^{1, *}$, and Nikolay \\ Menkov $^{2}$ \\ ${ }^{1}$ University of Food Technologies, Department of Tobacco, Sugar, Vegetable and Essential Oils, 4002 \\ Plovdiv, Bulgaria \\ ${ }^{2}$ University of Food Technologies, Department of Processes Engineering, 4002 Plovdiv, Bulgaria
}

\begin{abstract}
The moisture sorption capacity of tobacco seeds is decisive for their safe long-term storage; therefore, the analysis of the sorption isotherms, in a wide temperature and water activity range, is essential for seed quality maintenance in storage. In this study, the equilibrium sorption isotherms of tobacco ( N. tabacum L.) seeds, "Kroumovgrad 90" variety of Oriental tobacco, were determined. The experimental data were obtained by the static gravimetric method at different temperatures and water activities. Sorption isotherms showed a typical Type II sigmoidal profile, with a significant hysteresis effect and a decrease of seed sorption capacity with the increase of temperature. The best fitting with tobacco seed sorption isotherms were the modified Chung-Pfost (desorption) and Oswin (adsorption) models. The monolayer moisture content, important for the safe storage of tobacco seeds, was also determined. The outcomes from the study might be of practical use in tobacco seed conditioning and storage design.
\end{abstract}

\section{Introduction}

Tobacco (Nicotiana tabacum L.) is an important cash crop in Bulgaria, although the annual production has significantly dropped in the last decade, similar to the trends registered in other tobacco-producing European countries. Still, the official statistics for the last crop year available registered about 6000 ha tobacco-harvested area in Bulgaria, producing about 8600 tons of cured tobacco leaf [1]. More than half of the harvested area (about 3200 ha), responsible for about $60 \%$ of the country leaf production, is assigned to the small-leaf, highly aromatic Oriental tobacco (also called Turkish tobacco). In turn, approximately $80 \%$ of the Oriental tobacco production in Bulgaria is based on "Kroumovgrad 90" variety, commonly used as control in tobacco selection and in agroecological studies [2, 3]. Apart from the obvious use of tobacco leaf in cigarette production, the other aerial parts of the tobacco plant, e.g. flowers, seeds and stalks, offer many other options for alternative use [4]. Tobacco seeds in particular have the potential to be used in the production of biodiesel, edible oil, food and feed mixes, and other products [5-7], as they contain various nutrient

* Corresponding author: vpopova2000@abv.bg 
and bioactive metabolites, and are nicotine-free. Tobacco seeds of various genotypes have been found to contain about 30-49\% glyceride oil (with palmitic, oleic and linoleic acids being the dominant fatty acids), $0.3-1.7 \%$ phospholipids (phosphatidylinositol, phosphatidylcholine, and phosphatidylethanolamine as the primary components), $0.3-0.8 \%$ sterols (mainly $\beta$-sitosterol, stigmasterol and campesterol), 2-195 mg. $\mathrm{kg}^{-1}$ tocopherols (mainly $\gamma$-tocopherol), $18-41 \%$ protein (rich in essential amino acids), $3.5-21.8 \%$ fiber, macro and micro minerals $(\mathrm{K}, \mathrm{Mg}, \mathrm{Na}, \mathrm{Zn}, \mathrm{Cu})$, and other valuable nutrients $[5,6,8-15]$. The tiny tobacco seeds, $10000-16000$ units in a gram, constitute about $3.7 \%$ of the plant biomass in Oriental tobacco, thus providing an average yield of about $300 \mathrm{~kg} / \mathrm{ha}[16,17]$.

Despite their use potential in value-added products, tobacco seeds of approved varieties are currently collected only in the amounts necessary for the propagation of the tobacco plants; they are produced by certified farmers or companies on certified areas to assure the genetic authenticity of Bulgarian Oriental tobacco [18]. The rest of the seed biomass, together with tobacco stalks, turn into waste, disposed of, buried in the soil or burnt after leaf harvesting. Tobacco seeds tolerate long storage, provided that low moisture content is maintained; the seeds may remain viable even after 9-15 years if stored at a moisture content below 4\% along with desiccants [19]. It should be outlined that tobacco seeds for planting purposes are stored under regulated conditions (temperature, relative air humidity, packaging), as the national legislation sets a maximum seed moisture content of $10 \%$ [18], in view of sustaining the most important seed parameters, viability and germination vigor $[16,18]$. On the other hand, the seeds for potential alternative use are harvested at different ripeness stages (i.e. with varying moisture and chemical composition) and are stored by the farmers in unconditioned premises with varying air parameters (temperature, relative air humidity). During this period of long-term storage, tobacco seeds are exposed to the tangible risk of intensive biochemical and microbial transformations; processes, highly dependent on seed moisture sorption capacity, which deteriorate seed quality and have to be avoided, especially in the case of seed and seed by-products use for food and nutritional purposes. For that reason, the determination, analysis and understanding of tobacco seeds sorption isotherms, in a wide temperature and water activity range, is essential for the prediction of seed shelf life and seed quality maintenance in storage, e.g. for the estimation of seed oil quality (fatty acid, sterol, tocopherol composition), seed and seed cake protein quality (amino acid structure), carbohydrate and polysaccharide composition, and more. In fact, there are some studies on the sorption capacity and the equilibrium moisture content of tobacco seeds, carried out with different Bulgarian tobacco varieties, which provide models describing seed sorption isotherms [20,21]; however, those studies were conducted only with selected certified seeds, in the late $90 \mathrm{~s}$, and no contemporary data are available, nor data about discarded (non-standard, mass production) tobacco seeds.

Therefore, the objectives of this study were to determine the sorption isotherms of tobacco seeds intended for alternative use (by adsorption and desorption) in a water activity range between 0.2 and 0.8 , at three different temperatures, $10^{\circ} \mathrm{C}, 25^{\circ} \mathrm{C}$ and $40^{\circ} \mathrm{C}$, as well as to outline the best fitting isotherm model to experimental results. The outcomes from the study might be of practical interest in the overall tobacco plant usability and plant materials sorption studies.

\section{Materials and methods}

\subsection{Plant material}

Sorption isotherm experiments were carried out with authentic tobacco seeds (Nicotiana tabacum L.) of "Kroumovgrad 90" variety (Oriental type tobacco), supplied by a registered 
tobacco seed producer in the region of Kroumovgrad, South-East Bulgaria. They represented re-graded seeds, not suitable for planting purposes, according to the requirements of the Bulgarian Executive Agency for Seed Testing, Approbation and Control [18]. The seeds were kept in cotton cloth bags, in unprotected environment, i.e. at room temperature of about $22^{\circ} \mathrm{C}$ and relative air humidity of about $50 \%$, for a period of one year after collection. The bulk seed sample was with a purity of more than $98 \%$ and germination of more than $80 \%$. The initial moisture content of the seeds (air-dried) was $5.06 \pm 0.07 \%$, determined by drying to constant weight at $103 \pm 2^{\circ} \mathrm{C}$. Seed absolute weight, determined by weighing 1000 randomly selected air-dried seeds (precision of $\pm 0.0001 \mathrm{~g}$ ), was $0.0919 \pm 0.0018 \mathrm{~g}$ per 1000 seeds, corresponding to $10881.39 \pm 217.72$ seeds in $1 \mathrm{~g}$. The analyzed tobacco seeds contained $39.01 \pm 0.13 \%(w / w, D W)$ glyceride oil and $31.06 \pm 1.08 \%$ protein.

\subsection{Sorption isotherm design}

The static gravimetric method recommended for food products [22] was used to determine the equilibrium moisture content of tobacco seeds. In brief, samples of $0.5 \pm 0.05 \mathrm{~g}$ tobacco seeds in weighing bottles were put in hygrostats containing saturated aqueous salt solutions that maintained constant water activity $\left(a_{w}\right)$ in the closed vessel space (Fig. 1). Nine standard saturated salt solutions ( $\mathrm{LiCl}, \mathrm{CH}_{3} \mathrm{COOK}, \mathrm{MgCl}_{2}, \mathrm{~K}_{2} \mathrm{CO}_{3}, \mathrm{Mg}\left(\mathrm{NO}_{3}\right)_{2}, \mathrm{NaBr}, \mathrm{NaCl}$, $\mathrm{KBr}$, and $\mathrm{KCl}$ ) were used, maintaining above-surface water activities within the range between 0.113 and 0.823 [23]. Crystalline thymol in a glass dish placed in the hygrostat was used as an antimicrobial agent at $a_{w}>0.6$. The hygrostats were kept in the thermostats at three different temperatures, $10^{\circ} \mathrm{C}, 25^{\circ} \mathrm{C}$ and $40^{\circ} \mathrm{C}\left( \pm 0.1^{\circ} \mathrm{C}\right)$ until equilibrium was established (20 to 30 days). The equilibrium moisture content was determined gravimetrically (using a Mettler-Toledo precision balance, $\pm 0.0001 \mathrm{~g}$ ), after oven-drying at $105^{\circ} \mathrm{C}$ for 24 hours.

All measurements were carried out in a threefold repetition $(n=3)$.

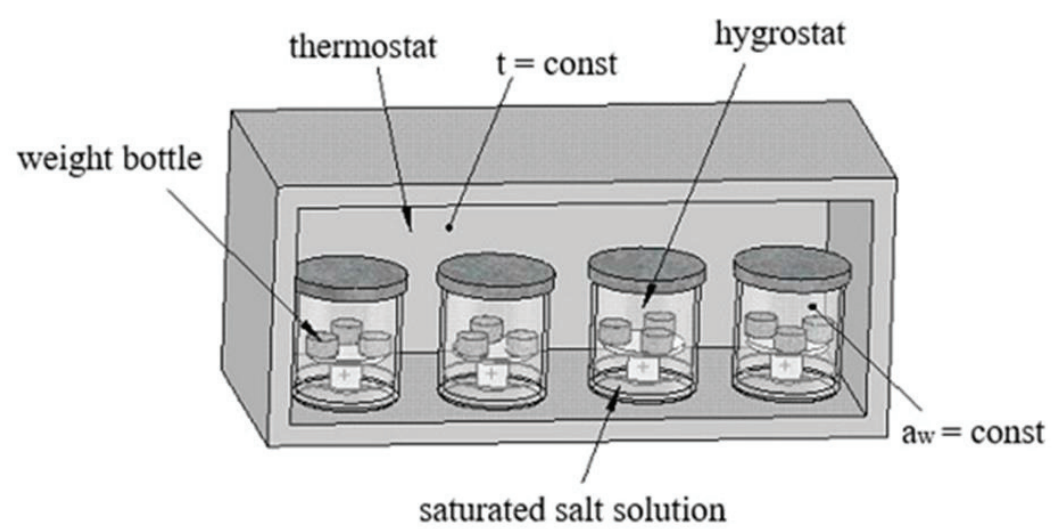

Fig. 1. Principle scheme of the experiment for tobacco seeds equilibrium moisture determination.

\subsection{Sorption isotherm modeling}

The experimental tobacco seed sorption isotherms were fitted with five three- and fiveparametric modified models (equations 1 to 5), recommended for plant materials [24], Chung-Pfost, Halsey, Oswin, Henderson, and Guggenheim-Anderson-de Boer (GAB) models, all accounting the influence of temperature on the mass transfer processes: 
Chung-Pfost

$$
a_{w}=\exp \left[\frac{-A}{t+B} \exp (-C M)\right]
$$

Halsey

$$
a_{w}=\exp \left[\frac{-\exp (A+B t)}{M^{C}}\right]
$$

Oswin

$$
M=(A+B t)\left(\frac{a_{w}}{1-a_{w}}\right)^{C}
$$

Henderson

$$
1-a_{w}=\exp \left[-A(t+B) M^{C}\right]
$$

GAB

$$
M=\frac{A B^{\prime} C^{\prime} a_{w}}{\left(1-B^{\prime} a_{w}\right)\left(1-B^{\prime} a_{w}+B^{\prime} C^{\prime} a_{w}\right)}
$$

The two specific coefficients in the modified GAB model, $B^{\prime}$ and $\mathrm{C}^{\prime}$, were expressed as follows:

$$
\begin{aligned}
& B^{\prime}=B \exp \left(\frac{h_{1}}{R T}\right) \\
& C^{\prime}=C \exp \left(\frac{h_{2}}{R T}\right)
\end{aligned}
$$

where $M$ is the equilibrium moisture, $\% \mathrm{DW} ; a_{w}$ - water activity; $T$ - temperature, $\mathrm{K} ; t-$ temperature, ${ }^{\circ} \mathrm{C} ; A, B, C, h_{1}$, and $h_{2}$ - constants; $R$ - the universal gas constant, $\mathrm{R}=8314$ $\mathrm{J} \cdot \mathrm{mol}^{-1} \cdot \mathrm{K}^{-1}$.

The respective coefficients in the models were determined by non-linear least square regression analysis, using STATISTICA software (Non-linear estimation procedure). The statistical criteria used in model suitability assessment were the mean relative error $(P, \%)$, the standard error of the estimate (SEE), the distribution of residuals (random or patterned, by graphical plotting of experimental and predicted values), and the coefficient of determination $\left(R^{2}\right)$.

The monolayer moisture content, a parameter important in terms of optimal seed storage, was determined in accordance with the Brunauer-Emmett-Teler (BET) model, effective for $a_{w}<0.5$ [22], as follows:

$$
M=\frac{M_{m} C a_{w}}{\left(1-a_{w}\right)\left(1-a_{w}+C a_{w}\right)}
$$

where $M_{m}$ is the monolayer moisture content, $\% \mathrm{DW}, a_{w}$ is the water activity and $C$ is a constant.

\section{Results and discussion}

The experimental adsorption and desorption isotherms for the tobacco seeds at $10^{\circ} \mathrm{C}, 25^{\circ} \mathrm{C}$ and $40^{\circ} \mathrm{C}$ are presented on Fig. 2 and Fig. 3, respectively. 


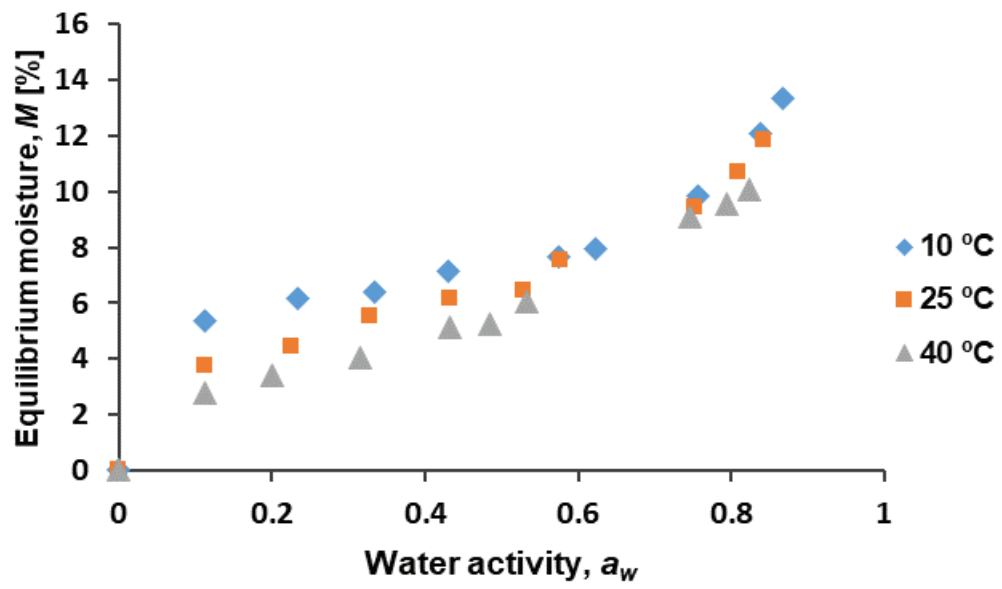

Fig. 2. Adsorption isotherms for tobacco seeds at three temperatures.

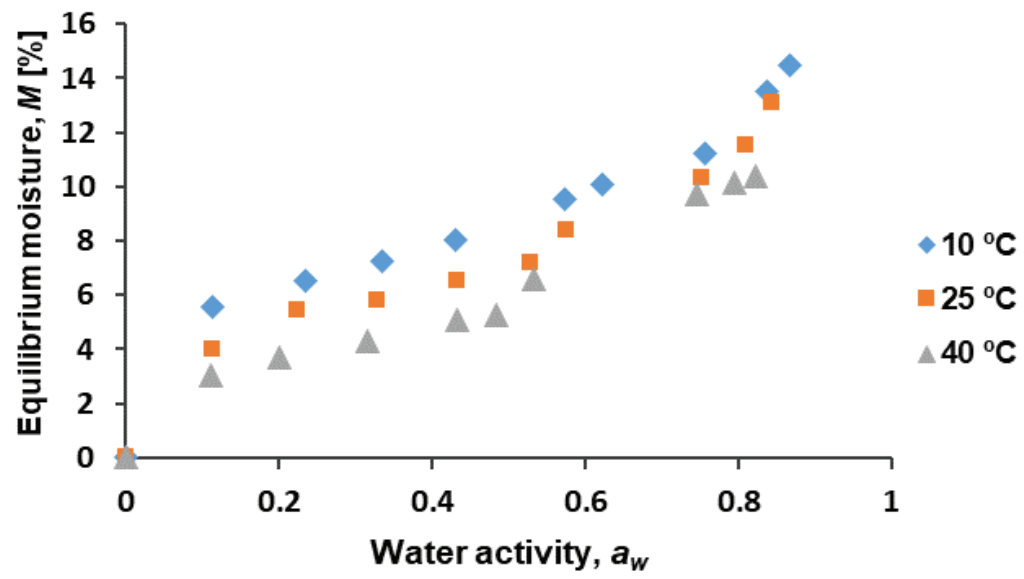

Fig. 3. Desorption isotherms for tobacco seeds at three temperatures.

As the figures suggested, all isotherms had the typical S-shaped profile, therefore they belonged to Type II isotherms, according to the classification of Brunauer [22], indicating multilayer moisture adsorption within the material $[25,26]$. The increase of equilibrium moisture with water activity is typical for agricultural materials, and seeds in particular, as found for example in lime seeds [25], cotton seeds [27], prickly pear seeds [28], flax seeds [29], hemp seeds [30], and others. At lower water activities, $a_{w}<0.53$, the increase in equilibrium moisture was slower, i.e. seeds gained relatively less moisture, while at $a_{w}>0.53$ the increase was much more intensive; therefore, seed quality would be affected stronger if storage is at relative air humidity over 55\%, similar to previous findings [28, 29]. Throughout the water activity range in the study, the sorption capacity of tobacco seeds decreased with the increase of temperature, therefore tobacco seeds were less hygroscopic at higher temperatures. An explanation of this is the temperature-driven decrease of the attractive forces between molecules and the detachment of water molecules from water binding cites [31]. The analysis of experimental data showed that tobacco seeds approached 
the threshold equilibrium moisture level of $10 \%$ for standard certified seeds [18] at water activity values of about 0.7 (adsorption) and 0.6 (desorption), regardless of temperature. The single equilibrium moisture values in the isotherms corresponded well with the high oil and high protein nature of tobacco seeds $(39.01 \pm 0.13 \%$ DW oil content, $31.06 \pm 1.08 \%$ protein content), i.e. being generally lower than those of starch-type seeds and grains [27].

Fig. 4 displays the comparison between the adsorption and desorption isotherms at a given temperature, $10^{\circ} \mathrm{C}$; similar comparisons were conducted for the isotherm patterns at the two higher temperatures, $25^{\circ} \mathrm{C}$ and $40^{\circ} \mathrm{C}$ (not presented separately, as the differences were only numerical).

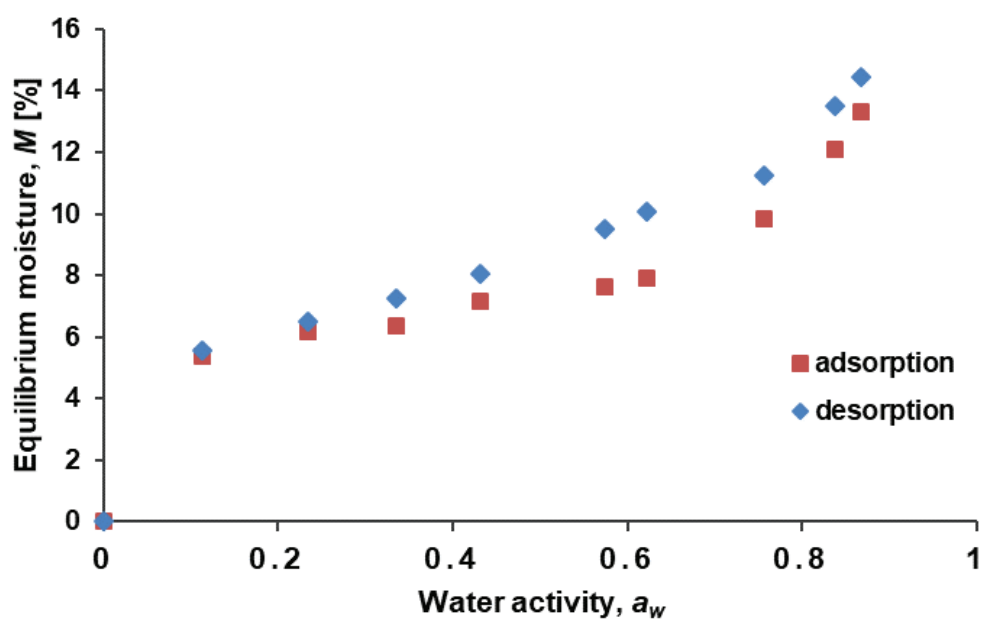

Fig. 4. Adsorption and desorption isotherms for tobacco seeds at $10^{\circ} \mathrm{C}$.

The plotted experimental values revealed a distinct hysteresis effect, which was assessed as statistically significant at a significance level $\alpha=0.05$ and water activity values higher than 0.3 . The hysteresis magnitude was less pronounced as the temperature increased $\left(10^{\circ} \mathrm{C}\right.$ vs. $25^{\circ} \mathrm{C}$ vs. $\left.40^{\circ} \mathrm{C}\right)$. Regardless of temperature, the absolute hysteresis values steadily exceeded $0.7 \%$ at water activities above 0.5 . These results were in compliance with previous observations for pea seeds [32], hemp seeds [30], pistachio nuts [33], and more. Therefore, our results suggested that those sorption capacity variations should be taken into account in tobacco seed storage, as it encompasses a long-term influence of fluctuating air humidity and temperature, characteristic for the unprotected storage environments in many climatic zones worldwide.

The results from the non-linear regression analysis of the sorption isotherms of tobacco seeds, tested against four of the modified isotherm models (equations 1 to 4) are presented in Table 1 (for the adsorption process) and Table 2 (for the desorption process), respectively. These tables display the obtained values of the coefficients in the respective model, together with the values of the mean relative error $(P)$, the standard error of the estimate $(S E E)$, the distribution of residuals, and the coefficient of determination $\left(R^{2}\right)$. Respectively, the values of the parameters in the modified GAB model (equation 5), as well as the assessment criteria, $P, S E E$, residuals, and $R^{2}$, are presented in Table 3 . 
Table 1. Model coefficients $(A, B, C)$, mean relative error $(P, \%)$, standard error of the estimate $(S E E)$, distribution of residuals, and coefficient of determination $\left(R^{2}\right)$ for the adsorption isotherms of tobacco seeds.

\begin{tabular}{|c|c|c|c|c|c|c|c|}
\hline Model & A & B & C & P & SEE & $\begin{array}{c}\text { Distribution } \\
\text { of residuals }\end{array}$ & $\mathbf{R}^{2}$ \\
\hline Chung-Pfost & 328.9661 & 22.88385 & 0.345541 & 2.52 & 0.58 & random & 0.9667 \\
\hline Oswin & 7.853005 & -0.045037 & 0.309634 & 0.82 & 0.57 & random & 0.9625 \\
\hline Halsey & 4.532681 & -0.025662 & 2.287651 & 7.28 & 0.79 & patterned & 0.9487 \\
\hline Henderson & 0.000185 & 2.9209 & 2.631784 & 10.33 & 1.23 & patterned & 0.8540 \\
\hline
\end{tabular}

Table 2. Model coefficients $(A, B, C)$, mean relative error $(P, \%)$, standard error of the estimate (SEE), distribution of residuals, and coefficient of determination $\left(R^{2}\right)$ for the desorption isotherms of tobacco seeds.

\begin{tabular}{|c|c|c|c|c|c|c|c|}
\hline Model & A & B & C & P & SEE & $\begin{array}{c}\text { Distribution } \\
\text { of residuals }\end{array}$ & $\mathbf{R}^{2}$ \\
\hline Chung-Pfost & 251.0101 & 13.99516 & 0.306062 & 5.22 & 0.47 & random & 0.9812 \\
\hline Oswin & 9.165054 & -0.069677 & 0.300945 & 6.59 & 0.55 & random & 0.9721 \\
\hline Halsey & 4.812732 & -0.031710 & 2.250399 & 6.28 & 0.99 & patterned & 0.9481 \\
\hline Henderson & 0.000257 & 6.917173 & 2.176796 & 10.58 & 1.25 & patterned & 0.9227 \\
\hline
\end{tabular}

Table 3. Coefficients $\left(A, B, C, h_{1}, h_{2}\right)$, mean relative error $(P, \%)$, standard error of the estimate (SEE), distribution of residuals, and coefficient of determination $\left(R^{2}\right)$ for the sorption isotherms of tobacco seeds fitted with the GAB model.

\begin{tabular}{|c|c|c|c|c|c|c|c|c|c|}
\hline Process & $\mathbf{A}$ & $\mathbf{B}$ & $\mathbf{C}$ & $\mathbf{h}_{\mathbf{1}}$ & $\mathbf{h}_{\mathbf{2}}$ & $\mathbf{P}$ & $\mathbf{S E E}$ & Residuals & $\mathbf{R}^{\mathbf{2}}$ \\
\hline Ads. & 4.678167 & 0.267195 & 0.000329 & 2408.645 & 27777.17 & 6.55 & 0.56 & random & 0.9667 \\
\hline Des. & 5.853125 & 0.113851 & 0.000462 & 4262.553 & 25925.05 & 7.14 & 0.62 & random & 0.9678 \\
\hline
\end{tabular}

The results from fitting the five modified models with the experimental data revealed that the lowest values of $P$ and $S E E$ were achieved with the Chung-Pfost model for the desorption process, while the respective quantitative criteria for the absorption process took minimal values with the Oswin model. The analysis of the graphs with the plotted values of the residuals unanimously indicated that both models, Oswin and Chung-Pfost, delivered a random distribution of the residuals (Tables 1 and 2). Therefore, both models were assessed as adequate for describing the sorption isotherms of tobacco seeds; still, the higher $R^{2}$ values provide reasonable grounds to recommend the application of Chung-Pfost model as the best fitting with the sorption profile of "Kroumovgrad 90" tobacco seeds. The GAB model, generally preferred due to its theoretical base and identified as the best fit in many 
seed isotherm analyses [28, 30], was less adequate for experimental data approximation in this study. Some variation was observed from the results by $[20,21]$, who recommended GAB and Oswin models as the most suitable for the seeds of other Bulgarian tobacco varieties. Thus, the results from this study supported previous findings that none of the common isotherm models is universally applicable for agricultural materials, even for seeds of similar types, e.g. high oil, starch, protein or fiber type [26].

In accordance with the objectives of the study, the monomolecular moisture content of tobacco seeds at three different temperatures was also determined. For that purpose, the BET model (equation 8) was transformed into its linear form, as expressed by the equation:

$$
\frac{a_{w}}{\left(1-a_{w}\right) M}=P+Q a_{w}
$$

The results from the linearization of the experimental data for the adsorption and desorption of tobacco seeds at $a_{w}<0.5$ are presented on Fig. 5 and Fig. 6, together with the respective regression equations and $R^{2}$ values.

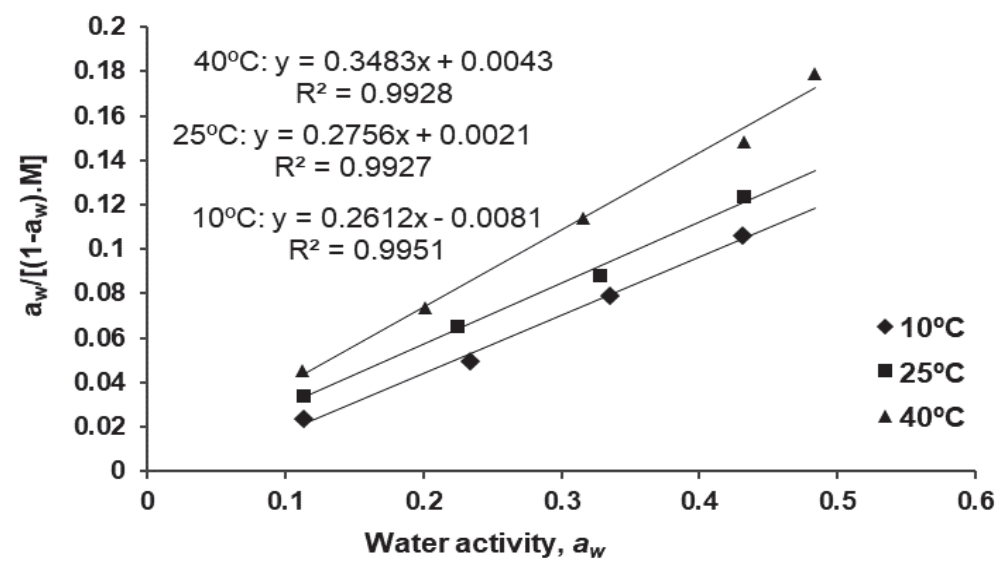

Fig. 5. Linearization of the BET model for the adsorption of tobacco seeds at three temperatures.

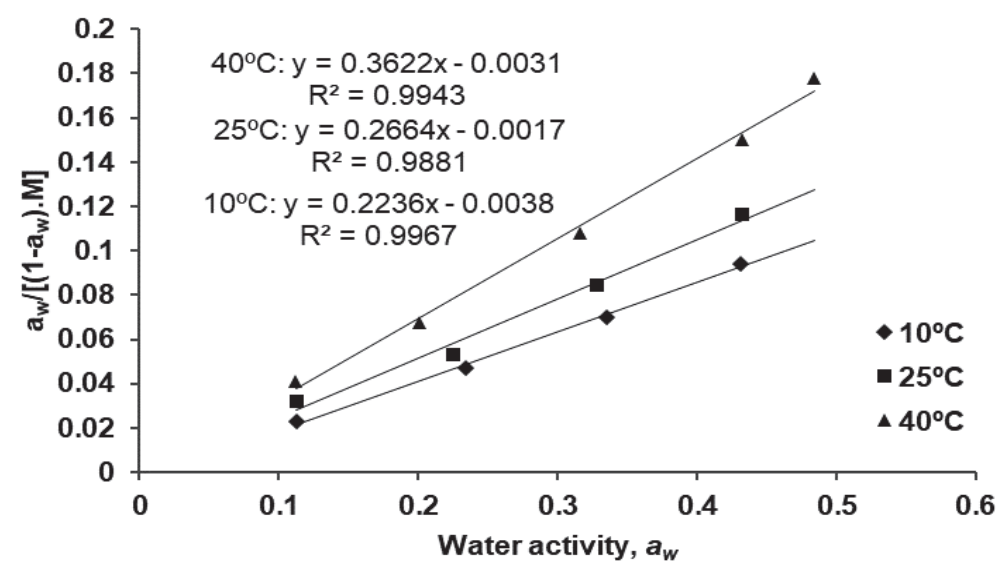

Fig. 6. Linearization of the BET model for the desorption of tobacco seeds at three temperatures. 
The coefficients in the linear equations shown on the graphs were used to calculate the monomolecular moisture content of tobacco seeds at the respective temperature, and the obtained values are presented in Table 4.

Table 4. Monomolecular moisture $\left(M_{m}, \% \mathrm{DW}\right)$ of tobacco seeds at different temperatures $\left(t,{ }^{\circ} \mathrm{C}\right)$, established by adsorption or desorption.

\begin{tabular}{|c|c|c|}
\hline \multirow{2}{*}{$\mathbf{t},{ }^{\circ} \mathbf{C}$} & \multicolumn{2}{|c|}{$\mathbf{M}_{\mathbf{m}}, \mathbf{\%} \mathbf{D W}$} \\
\cline { 2 - 3 } & Adsorption & Desorption \\
\hline 10 & 3.95 & 4.55 \\
\hline 25 & 3.60 & 3.78 \\
\hline 40 & 2.84 & 2.78 \\
\hline
\end{tabular}

As it is known, the monolayer moisture content is related to the possible initiation of biochemical and chemical reactions in plant materials, and is indicative of the amount of water strongly bound to the available sorption sites (i.e. biologically inert). The results in Table 4 demonstrated that the monomolecular moisture content of tobacco seeds decreased with the increase of temperature, as well as the presence of sorption hysteresis (i.e. the values set by desorption were higher than those by adsorption). Similar to the equilibrium moisture isotherms (Fig. 4), the hysteresis effect was most distinct at a temperature of $10^{\circ} \mathrm{C}$ (about 14\% relative difference), while being close to negligible at the other two temperatures. Moreover, the highest temperature in the study, $40^{\circ} \mathrm{C}$, denoted a partial exception of this tendency, as the monolayer moisture value by adsorption was higher than the respective value by desorption; still, the difference was minimal, below $2.5 \%$. The maximal values of the monolayer moisture, $3.95 \% \mathrm{DW}$ by adsorption and $4.55 \% \mathrm{DW}$ by desorption, set up the margins of tobacco seed safe storage for extended periods, as below those values water is biologically inert and unavailable for chemical and microbial processes.

\section{Conclusions}

The study provides experimental data and analysis of the equilibrium sorption isotherms of seeds of the most significant Bulgarian variety of Oriental tobacco, "Kroumovgrad 90", at three different temperatures. It was found that the sorption isotherms had the typical Sshaped profile, with a more intensive increase in equilibrium moisture at higher water activities, $a_{w}>0.53$. The study demonstrated that tobacco seeds were less hygroscopic at higher temperatures, as their sorption capacity decreased with the increase of temperature throughout the water activity range. A distinct hysteresis effect was observed in the adsorption and desorption isotherms, which turned out to be less pronounced with the increase of temperature. The general finding from the sorption isotherm modeling was that the sorption isotherms of tobacco seeds fitted best with the modified Chung-Pfost (desorption) and Oswin (adsorption) isotherm models, an outcome that could be further applied in tobacco seed conditioning and storage design. The maximal values of the monolayer moisture content of tobacco seeds were obtained, 3.95\% (by adsorption) and $4.55 \%$ (by desorption), thus indicating the range of biologically inert water in the long-time safe seed storage. 
The authors are most thankful to Prof. Albena Stoyanova, DSc, University of Food Technologies, Plovdiv, for the advice in conducting this study.

\section{References}

1. Ministry of Agriculture, Food and Forestry of the Republic of Bulgaria. https://www.mzh.government.bg/media/filer_public/2019/06/27/ra361publicationcrops2018_new.pdf (in Bulgarian)

2. N. Tahsin, V. Masheva, T. Ortomarova, T. Sci. Works USB-Plovdiv 16 ser. B, 4-8 (2013)

3. D. Vitanova, Y. Dyulgerski, Bulg. J. Crop Sci. 53(4), 49-56 (2016)

4. M. Banožić, J. Babić, S. Jokić, Ind. Crops Prod. 144, 112009 (2020)

5. S. Grisan, R. Polizzotto, P. Raiola, S. Cristiani, F. Ventura, F. di Licia, M. Zuin, S. Tommasini, R. Morbidelli, F. Damiani, F. Pupilli, M. Bellucci, Agron. Sustain. Dev. 36, 54-55 (2016)

6. L. Rossi, E. Fusi, G. Baldi, C. Fogher, Open J. Vet. Med. 3, 73-78 (2013)

7. Z. Xie, M. Whent, H. Lutterodt, Y. Niu, M. Slavin, R. Kratochvil, L. Yu, J. Agric. Food Chem. 59(18), 9877-9884 (2011)

8. M. Ali, M. Abu Sayeed, R. Kumar Roy, S. Yeasmin, A. Mohal Khan, Asian J. Biochem. 3(4), 203-212 (2008)

9. N. Frega, F. Bocci, L. Conte, F. Testa, J. Am. Oil Chem. Soc. 68, 29-33 (1991)

10. M. Mohammad, N. Tahir, Annu. Res. Rev. Biol. 4(9), 1480-1489 (2014)

11. A. Mukhtar, H. Ullah, H. Mukhtar, Asian J. Chem. 18(1), 20-24 (2006)

12. A. Mukhtar, H. Ullah, H. Mukhtar, Chin. J. Chem. 25, 705-708 (2007)

13. M. Zlatanov, N. Menkov, Tutun/Tobacco 52(9-10), 284-287 (2002)

14. M. Zlatanov, M. Angelova, G. Antova, Sci. Agric. Bohem. 38(2), 69-72 (2007)

15. M. Zlatanov, M. Angelova, G. Antova, Bulg. J. Agric. Sci. 13, 539-544 (2007)

16. M.L.M. de Carvalho, C.A. Lopes, A.M.P. Ribeiro, M.C. Vasconcelos, J. Seed Sci. 40(3), 296-303 (2018)

17. H. Bozukov, Sci. Works USB-Kardzhali 5, 19-23 (2014) (in Bulgarian)

18. Ministry of Agriculture, Food and Forestry of the Republic of Bulgaria, State Gazette of the Republic of Bulgaria, 60 (2004)

19. K.N. Rao, K.S. Raju, D.P. Babu, Indian J. Agric. Res. 37(4), 235-244 (2003)

20. N.D. Menkov, J. Agric. Eng. Res. 72(4), 347-353 (1999)

21. N.D. Menkov, K.T. Dinkov, J. Agric. Eng. Res. 74(3), 261-266 (1999)

22. L.N. Bell, T.P. Labuza, Moisture sorption: Practical aspects of isotherm measurement and use (American Association of Cereal Chemists Inc., 2000)

23. L. Greenspan, J. Res. Natl. Bur. Stand. 81A, 89-96 (1977)

24. ASAE Standard D245.5. (ASAE, St. Joseph, Michigan, 1997)

25. H. Váquiro, S. Simal, G. Carvalho, J. Telis-Romero, EuroDrying'2011 (Palma, Balearic Island, Spain, 26-28 October 2011)

26. R.D. Andrade, R. Lemus, C.E. Pérez, Vitae 18(3), 325-334 (2011)

27. M.A. Bakhtavar, I. Afzal, S.M.A. Basra, PLoS ONE 14(2), e0207569 (2019) 
28. L. Hassini, E. Bettaieb, H. Desmorieux, S. Sandoval Torres, T. Amira, Ind. Crops Prod. 67, 457-465 (2015)

29. M.C. da Costa Valente, R.A. do Nascimento, E.B. Santana, L.J.G. de Faria, C.M.L. Costa, Rev. Ciênc. Agron. 51(2), e20186086 (2020)

30. F. Jian, D. Divagar, J. Mhaiki, D.S. Jayas, P.G. Fields, N.D.G. White, Food Sci Nutr. 6, 1629-1640 (2018)

31. C.S. Ethmane Kane, M. Kouhila, A. Lamharrar, A. Idlimam, A. Mimet, Rev. Energies Renouv. 11, 181-195 (2008)

32. C. Chen, J. Food Eng. 58, 45-51 (2003)

33. A.A. Zomorodian, R.A. Tavakoli, J. Agric. Sci. Technol. 9, 259-265 (2007) 